\title{
Kitle ve Karın Ağrısı ile Kendisini Gösteren Mezenterik Pannikülit
}

\author{
Mesenteric Panniculitis That Manifests it self With Mass and Abdominal Pain:
}

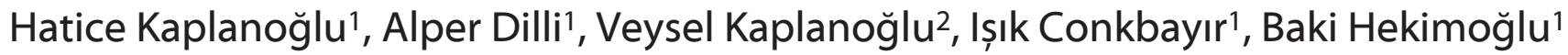

I S.B. Dıșkapı Yıldırım Beyazıt Eğitim ve Araștırma Hastanesi,
Radyoloji Kliniği, Ankara
2 S.B. Numune Eğitim ve Araștırma Hastanesi, Radyoloji Kliniği, Ankara
Geliș tarihi : 23.05.2014 • Kabul tarihi: 09.01.2014

İletișim

Uz.Dr.Alper DiLL

Radyoloji Kliniği

Tel : 03123260010

E-Posta Adresi : alperdilli@yahoo.com

S.B. Dıșkapı Yıldırım Beyazıt Eğitim ve Araștırma Hastanesi
Mezenterik pannikülit, etyolojisi bilinmeyen, benign ve nadir bir durumdur. Kronik inflamatuar bir
süreç olup mezenterik yağ dokusunu etkiler. lyi tanımlanmıș 2 tipi vardır. Birincisi akut ve subakut
formu mezenterik pannikülit olarak ve ikincisi ise kronik formu retraktil veya sklerozan mezenterit
olarak bilinir. Mezenterik pannikülit spesifik klinik bulgu ve tipik semptomları olmadığı için, yanlıș
tanı konulması ve gözden kaçması çok kolaydır. Doğru tanısı eksploratif laparatomi ve patolojik
incelemeyle konur. Literatürde preoperatif olarak tanı konulabilen çok az sayıda olgu bildirilmiștir.
Biz preoperatif olarak bilgisayarlı tomografi (BT) tetkiki ile radyolojik tanısını koyduğumuz üç
mezenterik pannikülit olgusunun radyolojik bulgularını ve klinik önemini sunuyoruz.
Anahtar Sözcükler: Mezenterik Pannikülit, Bilgisayarlı Tomografi, Ultrasonografi
Mesenteric panniculitis; which etiology is unknown, is a rare and benign condition. Being a chronic
inflammatory process, it affects the mesenteric adipose tissue. There are two well defined types of
mesenteric panniculitis. First one is known as acute and subacute form of mesenteric panniculitis
and second one is known as chronic retractile form or sclerosing mesenteritis. Since mesenteric
panniculitis does not have specific clinical outcome or typical symptoms, it is extremely easy to fail to
notice or to lead to a misdiagnosis. The true diagnosis of mesenteric panniculitis is established by
explorative laparotomy and pathological examination. There are very few stated cases which can be
diagnosed in literature. We; preoperatively, present the significance of three mesenteric panniculitis
cases radiological symptoms and clinical importance which we have radiologically diagnosed
preoperatively with the computed tomography examination.
Key Words: Mesenteric Panniculitis, Computed Tomography, Ultrasonography

Mezenterik pannikülit oldukça nadir bildirilmiştir (1). İlk defa 1920’li y1llarda Jura tarafindan tanımlanmıştır (2). Mezenterik yağ dokuyu tutan benign, fibrotik ve kronik inflamatuar bir durumdur (3). Nadiren mezokolon, peripankreatik alan, omentum, retroperitoneum veya pelvisi de tutabilir (4). Hastalığın insidansının yaşla birlikte arttığı ve 6 . ve 7. dekadlarda daha s1k görüldüğü bildirilmiştir (5). Klinik bulgular genelde nonspesifik ve atipiktir. Bununla birlikte karında rahatsızlık hissi, kitle, ateş, barsak alışkanlığında değişiklikler, kanama, şilöz asit veya kilo kayb1 gibi semptomlar görülebilir $(1,3)$. Etyolojisi kesin olarak bilinmemekle birlikte, bağımsız olarak gelişebileceği veya enfeksiyon, travma ve iskemi gibi faktörlerce tetiklenebileceği düşünülmektedir (1, 5, 6). Histopatolojisi 3 faz şeklinde tanımlanmıştır. Başlangıçta yağ nekrozu görülür ve mezenterik lipodistrofi olarak adlandirılır. Bunu inflamasyonun derinleşmesiyle mezenterik pannikülit izler. Son aşamada fibrozisi takiben mezenterik retraksiyon ve kisalma meydana gelir, sklerozan mezenterit olarak adlandirllır (1). Birçok olguda histopatolojik incelemede mezenterik yağ nekrozu (lipodistrofi), kronik nonspesifik inflamasyon (pannikülit) ve fibrozisden (sklerozan mezenterit) oluşan üç aşamaya ait değişiklikler birlikte izlenir. Genellikle mezenterin farklı bölgelerini farklı oranlarda etkilenmiştir (3).

Nadiren tanımlanan bir durum olmasina rağmen, mezenterik pannikülit tanısı çok kesitli BT' nin gelişimi ve daha sık kullanılmasıyla birlikte artmıștır. Literatürde operasyon olmadan tanı konulabilen çok az sayıda olgu bildirilmiștir. Görüntüleme yöntemlerinden BT tetkiki ile operasyon olmadan radyolojik olarak tanısını koyduğumuz klinik prezantasyonları farklı üç mezenterik 
pannikülit olgusunun BT görüntüleme bulguları sunulmuştur.

\section{OLGU SUNUMLARI}

Olgu 1: Yetmiş sekiz yaşında erkek hasta, karında şişlik, halsizlik, iştahsızlık, sirta vuran ve son haftalarda giderek şiddeti artan ağrı ve genel durumunda ciddi kötüleşme şikâyetleri ile hastanemize başvurdu. Fizik muayenesinde, batin asit nedeniyle distandü görünümdeydi. Alt karında hassasiyet mevcuttu. Laboratuar testlerinde, demir eksikliği anemisi (Hgb; 11.8g/dL), orta derecede lökositoz (Wbc, 15.500/ $\mu \mathrm{L}$ ), nötrofil sayisında artış $(11.500 / \mu \mathrm{L})$, Creaktif proteinde (CRP) artış (114 $\mathrm{mg} / \mathrm{L})$, eritrosit sedimantasyon hızında (ESR) (45 mm/saat) artış, tümör belirteçlerinden CEA (2985 ng/mL), CA-19-9 (3994 u/mL), CA$125(220 \mathrm{U} / \mathrm{mL})$ seviyelerinde yükselme saptandi. Hastanin Özgeçmişinde hipertansiyon, koroner arter hastalığ1 (KAH), kronik obstrüktif akciğer hastalığ1 (KOAH) mevcuttu. PA akciğer radyografisi normal olarak değerlendirildi.

Abdominal Ultrasonografi

incelemesinde, karında yaygin asit mayi ve pankreas başı anterior komşuluğunda $\quad 55 \times 45 \quad \mathrm{~mm}$ boyutlarında hiperekojen kitle saptandi. Pankreas malign neoplazisi ön tanısıla hastaya oral ve intravenöz kontrast madde verilerek $6,5 \mathrm{~mm}$ kesit kalınlığ1 ve $5 \mathrm{~mm}$ kesit aralığ1 ile torokoabdominal BT çekildi. Toraks kesitlerinde; bilateral plevral efüzyon ve her iki akciğer parankiminde çapları $5 \mathrm{~mm}$ altında bir kaç adet parankimal nodül, abdomen kesitlerinde; asit mayi, anterior prepankreatik alanda mezenterik vasküler yapıları kuşatan, komşu ince barsak anslarını posterolaterale iten, porta hepatisi ve peripankreatik alanı infiltre eden, heterojen hiperdens lobüle konturlu $14 \times 7 \mathrm{~cm}$ boyutlarında santralinde hipodens alanları bulunan kitle izlendi (Şekil 1). Bu kitlenin pankreas kitlesi olmadığı, öncelikle mezenterik pannikülit olduğu düşünüldü. Ayrica mezenterik, portal hilusta ve paraçölyak bir kısmının santrali nekrotik birkaç adet lenfadenopati (LAP) saptandi. Peritonda kontrastlanma ve peritoneal implant kaydedildi (Şekil 2).

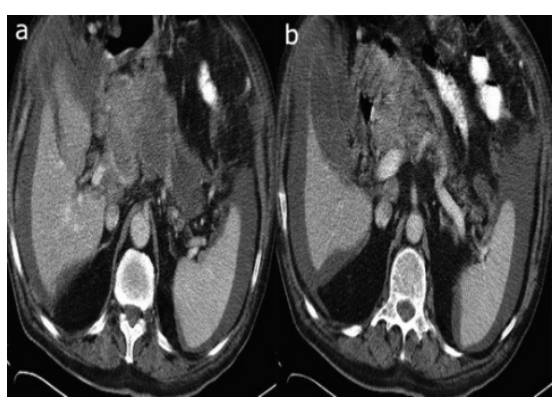

Şekil 1: (a) Anterior prepankreatik alanda heterojen hiperdens kitle, (b) kitle mezenterik vasküler yapıları sarıyor, vena porta hepatisi ve peripankreatik alanı infiltre ediyor.

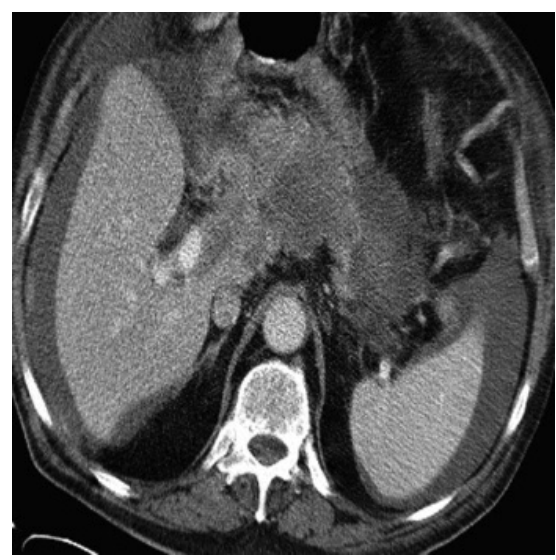

Şekil 2: Karında serbest sıvı, peritonda kontrastlanma ve peritoneal implant

Olguya boşaltıcı parasentez yapıldı. Asit mayinde sitoloji ve kültür çalışıldı. Kültüründe üreme olmadi. Sitoloji incelemesinde; mezotel hücreleri, inflamatuar hücreler ve arada atipik hücreler kaydedildi. Bulgular malignite açısından anlamlı olarak değerlendirildi. Mide endoskopisi yapıldı. Mide kardiyasında mukoza çepeçevre ödemli, hiperemik ve irregüler görünümde saptandı. Çok sayıda biyopsi yapılarak örnekler alınd. Biyopsi sonucu intestinal tip adenokanser geldi. Kitleye BT eşliğinde biyopsi yapıldı ve sonucunda; yağ nekrozu, hemorajik odaklar, sklerozan fibrozis, mononükleer hücre infiltrasyonu ve proliferasyonu, lipid yüklü makrofajlar içeren iltihabi fibroadipoz doku, yani mezenterik pannikülit olarak raporlandi. Olgu tedavisi için onkoloji servisine yatırild.

Olgu 2: Atmış sekiz yaşında erkek hasta, epigastrik ve umblikal bölgede ağrı ve rahatsızlık hissi ile hastanemize başvurdu. Fizik muayene ve laboratuar testlerinde anormal bulgu saptanmadi. Özgeçmişinde benign prostat hiperplazisi (BPH), hipertansiyon, KAH, sigara kullanımı vard. Yapilan US incelemesinde orta hatta prepankreatik ve mezenterik sahada belirgin yağlanma saptandi. Olguya yapilan abdominal BT tetkikinde, ince barsak mezenter kökünde vasküler yapıları saran, sol paraaortik alana doğru uzanan, içerisinde çok sayıda dağınık yerleşimli, milimetrik boyutta yumuşak doku dansitesinde nodüler lezyonun izlendiği, mezenterik yağ dokuya spiküler uzanımlar gösteren, heterojen dansitede kapsüle kitle lezyonu izlendi (Şekil 3, Şekil 4) ve mezenterik pannikülit olarak yorumlandı. Yağlı kitleyi parsiyel olarak çevreleyen tümöral psödokapsül ile uyumlu hiperdens çizgi şeklinde hat izlendi. Vasküler yapilar ve yumuşak doku dansitesinde nodüler lezyonlar çevresinde halo şeklinde yağ dokusu (fat ring sign) mevcuttu. Ince barsak anslar1 perifere doğru itilmiş durumdaydı. Olgunun yapilacak olan biyopsi veya cerrahi tedaviyi kabul etmemesi nedeniyle histopatolojik doğrulaması yapilamadı.

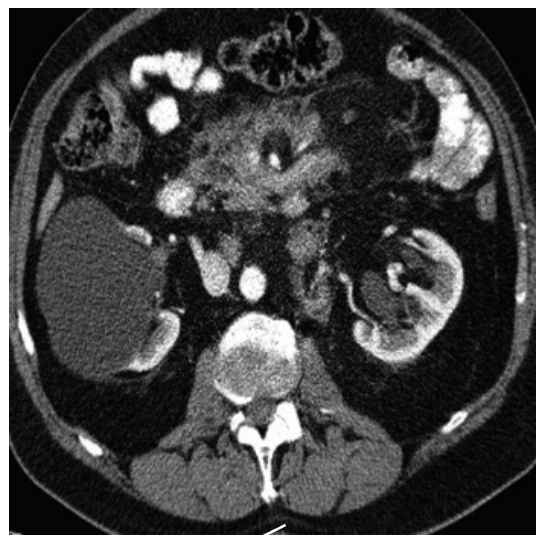

Şekil 3: Mezenter kökünde vasküler yapıları saran, heterojen dansitede kitle lezyonu, vasküler yapı çevresinde ise yağ dokunun korunduğu izleniyor (fat ring sign) 


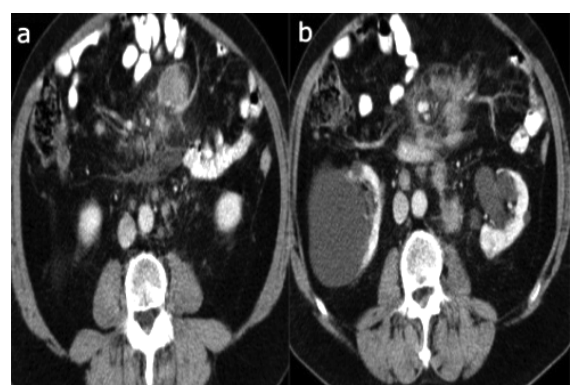

Şekil 4: (a) Kitlenin içerisinde çok sayıda milimetrik boyutta yumuşak doku dansitesinde nodüler lezyon, (b) kitleyi parsiyel olarak çevreleyen hiperdens çizgi şeklinde hat (tümöral psödokapsül)

Olgu 3: Atmış beş yaşında erkek olgu, bir haftadır devam eden karın ağrısı ve iştahsızlık şikâyeti ile hastanemize başvurdu. FM'sinde karında hassasiyet mevcuttu. Laboratuar bulgularında lökositoz dışında anlamlı bulgu yoktu. Özgeçmişinde diyabet, peptik ülser hastalıkları mevcuttu. Abdominal US' de sağ parakolik ve pelvik lokalizasyonda serbest siv1 ve ileal ans duvarlarinda ödem ile uyumlu duvar kalınlaşması izlendi. Oral ve intravenöz kontrast madde verilerek $6,5 \mathrm{~mm}$ kesit kalınlığ1 ve 5 mm kesit aralığı ile yapilan abdominal BT' sinde; mezenter kökü düzeyinde vasküler yapıları çevreleyen, mezenterik yağ dokuya spiküler uzanımlar gösteren heterojen hiperdens yumuşak doku dansitesinde kitle lezyonu mevcuttu (Şekil 5). Kitle içerisinde çok sayıda dağınık yerleşimli, milimetrik boyutta yumuşak doku dansitesinde nodüler lezyon izlendi. Kitleyi çevreleyen tümöral psödokapsül ile uyumlu hiperdens çizgi şeklinde hat izlendi. Görünüm mezenterik pannikülit ile uyumlu değerlendirildi. Portal ven ve süperior mezenterik ven lümeninde tromboz mevcuttu (Şekil 6). Ayrica subhepatik ve parakolik minimal serbest sivı izlendi.

Abdominal B'T görüntüleme bulgularına rağmen, rahatlamayan ve akut karın bulgular1 devam eden hastaya laparotomi yapıldı. Laparotomide ince barsaklarin nekroze mezosunun ileri derecede ödemli olduğu izlendi. Mezenterik pannikülit tanısı doğrulandi. Olguya ince barsak rezeksiyonu yapıldı. Patoloji sonucu, yağ nekrozu, inflamatuar mononukleer hücre infiltrasyonu, fibroblast proliferasyonu içeren fibroadipoz doku ve konjesyon bulgular1 ile mezenterik pannikülit olarak değerlendirildi.

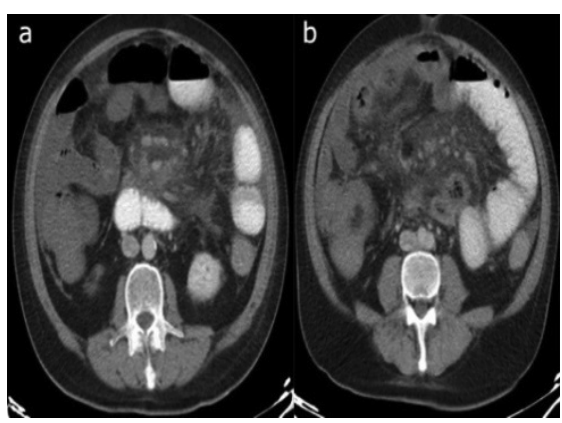

Şekil 5: (a) Mezenterik yağ dokuya spiküler uzanımlar gösteren heterojen hiperdens kitle, (b) kitle içerisinde çok sayıda milimetrik boyutta yumuşak doku dansitesinde nodüler lezyon

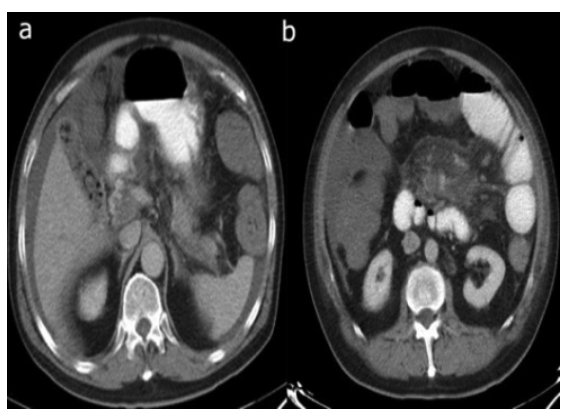

Şekil 6: (a) Portal ven lümeninde tromboz, (b) süperior mezenterik ven lümeninde tromboz, kitleyi çevreleyen tümöral psödokapsül

\section{TARTIȘMA}

Mezenterik pannikülit, etyoloji kesin olarak bilinmeyen, mezenterik yağ dokuyu tutan kronik nonspesifik inflamayon, yağ nekrozu ve fibrozisten oluşan tümör benzeri kitle ile karakterize bir hastaliktır (3, 5). İlk defa 1920'lerde Jura tarafindan tanımlanmıştır (2). Yedi yüz'ün üzerinde olguda yapilan otopsi çalışmasında popülasyonun $\% 1$ ' inde saptanmıştır (6). Hastalığı tanımlamak için literatürde mezenterik pannikülit, sklerozan mezenterit, fibröz mezenterit, retraktil mezenterit, liposklerotik mezenterit, ksantogranülamatöz mezenter, inflamatuar psödotümör, sistemik nodüler pannikülit, mezenterik lipogranülom, sklerozan lipogranülomatozis, mezenterik lipodistrofi gibi çeşitli isimler kullanılmıştır (5). Mezenterin inflamatuar hastalığ1 histolojik olarak ilerleyici bir dizi değişiklikle karakterizedir. Başlangıçta mezenter lipid dolu makrofajlarca infiltre edilir ve mezenterik lipodistrofi olarak adlandirilır. $\mathrm{Bu}$ durumun daha da ilerlemesi ve üzerine inflamasyon ve yağ nekrozunun eklenmesiyle mezenterik pannikülit olarak bilinen akut ve subakut formu ortaya çıkar. Fibrozis ve nekrozun ortaya çıtığı, mezenterde kisalmanın oluştuğu kronik formu ise retraktil veya sklerozan mezenterit olarak bilinir (1, 7). Bizim olgularımızda 2'sinin histopatolojik tanısı konmuş olup, inflamasyon ve yă̆ nekrozu daha baskın komponentlerdi, mezenterik pannikülit olarak tanımlandı. Bu nedenle biz de mezenterik pannikülit terimini kullandık.

Klinik bulgular nonspesifik ve atipiktir. Karında rahatsızlık hissi, kronik karın ağrısı, barsak alışkanlığında değişiklik, kanama, karın içi kitle, ateş, bulantı, kusma, şilöz asit ve kilo kaybı başlıca klinik belirti ve şikâyetlerdir (1-8). Literatürde en s1k bildirilen şikâyet karın ağrısıdır (9), üç olgumuzda da karın ağrısı şikâyeti ön plandaydı.

Hastalığın insidansının yaşla birlikte arttığ1 ve 6 . ve 7 . dekadlarda daha s1k görüldüğü bildirilmiştir (5). İki olgumuz 60 yaşının ve bir olgumuz ise 70 yaşın üstündeydi. Bazı serilerde erkeklerde (2:1 ve 3:1) daha fazla görüldüğü bildirilmiştir (5). Ü̉ç olgumuzda erkekti.

Etyolojisi kesin olarak bilinmemektedir. Bağımsız olarak gelişebileceği veya enfeksiyon, travma ve iskemi gibi faktörlerce tetiklenebileceği bildirilmiştir (1, 5, 6). Bunlara ek olarak geçirilmiş cerrahi sonrası, hipersensivite reaksiyonlar1, travma, ilaçlar, vaskülitler, A vitaminozisi, termal veya kimyasal yaralanmalar, pankreatit, otoimmün hastalıklar, malign tümörler (özellikle lenfoma), paraneoplastik sendrom, vaskülitler ve granülomatöz hastalıklar, tütün 
kullanımı, safra ve idrar kaçağı da predispozan faktörler olarak belirtilmiştir (1, 4, 10-14). Daskalogiannaki ve ark. çalışmalarında mezenterik pannikülit ile malignite arasinda \%69,3 oranında birliktelik bildirmişlerdir (9). Canyiğit ve ark. çalışmalarında: \%17,6 oranında malignite, \%33,3 oranında daha önce geçirilmiş operasyonlar, $\% 39,2$ oraninda sigara, \%17,6 oraninda $\mathrm{KAH}, \% 19,6$ oraninda ürolitiazis, $\% 35,2$ oranında hipertansiyon, $\% 25,5$ oranında hiperlipidemi, $\% 21,5$ oranında diyabet ile mezenterik pannikülit arasında ilişkili saptamışlardır (5). Olgularımızdan birinde hastane başvurusu sonrası yapılan endoskopik tetkikte mide adenokarsinomu saptand. Aynı hastamizda hipertansiyon, $\mathrm{KAH}, \mathrm{KOAH}$ mevcuttu. İkinci olgumuzda BPH, hipertansiyon, $\mathrm{KAH}$ ve kronik sigara kullanımı vardı. Üçüncü olgumuzda ise diyabet, peptik ülser ve safra kesesinde taş mevcuttu.

Laboratuar bulguları sıklıkla normaldir. Çalışmalarda ESR ve/veya diğer akut faz reaktanlarında artış olabileceği bildirilmiştir (3). Olgularımızdan ikisinde ESR, birinde ise CRP seviyelerinde artış saptandi. Bir olgumuzda laboratuar bulguları normaldi.

Sklerozan mezenterit birçok olguda barsak mezenterini tutmasina rağmen, aynı zamanda mezokolon, peripankreatik bölge, omentum, retroperiton ve pelvisi de tutabilir (4). Olgularımızın ikisinde kitle mezenter kökünde yerleşimli ve birinde prepankreatik alanda lokalizeydi.

US ve BT tetkikleri mezenterik pannikülitin değerlendirilmesinde ve tanısında kullanılmaktadır. Mezenterik pannikülitin US tetkikinde, mezenter kökünde iyi sınırlı, homojen hiperekoik yağlı kitle şeklinde izlenir. Mezenter kompresyonunun azalmas1 bir diğer tanıya yardımcı ipucudur. Renkli Doppler US incelemede mezenterik damarların kitle içerisinde olduğu izlenir ve jejunal ve ileal vasküler dallarda yüksek dirençli akım saptanır. Ancak tanıda US bulguları nonspesifik olup kesitsel yöntemlerle desteklenmelidir (7, 11, 12). Bir olgumuzda US tetkikinde; karında yaygın asit mayi ve pankreas başı komşuluğunda anteriorda $55 \times 45 \mathrm{~mm}$ boyutlarında heterojen hiperekoik kitle saptand1. İkinci olgumuzda, orta hatta prepankreatik ve mezenterik alanda belirgin yağlanma mevcuttu. Son olgumuzda ise karin alt kadranlarda serbest siv1 ve ileal ans duvarlarında ödem lehine duvar kalınlaşması vardı.

BT görünümleri hastalı̆̆ın evresine bağlı olarak mezenterik yağ doku dansitesinde belirgin artıştan, solid yumuşak doku kitlesi şeklindeki görünüme kadar değişmektedir. Normal mezenterik yağ doku dansitesi subkutanöz ve retroperitoneal yağ dansitesi ile benzerdir (Hounsfield unit (HU): 100 ila -160 ). Mezenterik yağ doku dansitesindeki artma puslu ve bulanık mezenter olarak adlandırılır (5) ve sklerozan mezenterit için anlamlıdır. Histopatolojik olarak mezenterik yağ dokuda difüz inflamasyon dominant ise, mezenter kökünde lokalize, barsak anslarına komşu heterojen, enkapsüle, solid yumuşak doku kitlesi ve kitle çevresinde mezenter kökü boyunca uzanan difüz serpijinöz yumuşak doku dansiteleri görülür. Bu yumuşak doku dansiteleri inflamatuar infiltrasyonu ve fibrotik alanlar1 gösterir (7). Kitle porta hepatisi ve peripankreatik alanı infiltre edebilir. Kitle mezenterik damarları çevreler fakat mezenterik damarlarda invazyon ve yer değişikliğine neden olmaz. Ayrıca yağlı kitle içerisinde çok sayıda dağınık yerleşimli, çapları 5 mm' nin altında, yumuşak doku dansitesinde küçük nodüler lezyonlar izlenir. Ayrıca mezenterik damarları ve nodüler lezyonları çevreleyen, hipodens halo şeklinde yağ dokusu izlenir (5, 9, 15-17). Bu görünüm "fat ring sign" olarak adlandirilır. Bu bulgu sklerozan mezenteriti, mezenteri tutan lenfoma, karsinoid tümör ve karsinomatozis gibi diğer hastaliklardan ayıric1 tanisinda yardımcıdır (15). Yağlı kitleyi kısmi olarak çevreleyen hiperdens çizgi şeklinde hat izlenir bu tümöral psödokapsül olarak adlandırılır (5, 9, 15-17).

Şayet hastalıkta histopatolojik olarak fibrozis baskin olan komponentse, BT tetkikinde yine yukarıda tanımlanan yumuşak doku dansitesinde kitle saptanır. Ancak kitle içerisinde küçük kalsifikasyon odakları patolojik inceleme esnasinda izlenir. $\mathrm{Bu}$ kalsifikasyonların BT tetkiki ile tanımlanması oldukça nadirdir. Literatürde radyolojik olarak kalsifikasyonun tanımlandığ1 2 olgu bildirilmiştir (7).

Olgularımızdan ikisinde mezenterik pannikülit mezenter kökünde yerleşimli, diğer olguda ise prepankreatik alanda yerleşimli hipoekoik kitle saptanmıştı. Üç olguda da kitle mezenterik damarları çevreliyordu ancak damarlarda itilme bulgusu saptanmadı. Üç olguda da yağlı doku içerisinde mezenterik lenf nodları izlendi. Ancak olgulardan ikisinde mezenterik damarları ve lenf nodlarını saran hipoekoik halo saptandı. Üç olguda da tümöral psödokapsül mevcuttu.

Tariflenen BT bulguları kuvvetle mezenterik panniküliti düşündürse de spesifik değildir. Bu nedenle mezenterik lenf nodunun kısa aksını 10 mm' yi geçtiği olgularda maligniteyi ekarte etmek için mutlaka biyopsi yapilmalıdır. Mezenterik pannikülitte mezenterik lenf nodunun kisa aks1 (ortalama $6,4 \mathrm{~mm}$ ) $10 \mathrm{~mm}$ ' nin altindadir (5, 11, 17). Olgularımızdan birinde lenf nodunun çap1 $10 \mathrm{~mm}$ nin üstündeydi. Bu olguya daha sonra yapilan endoskopik inceleme ile mide adenokarsinom tanisi kondu, ayrica BT eşliğinde yapılan biyopsi ile mezenterik pannikülit tanısı doğrulandı. Diğer iki olgumuzda lenf nodlarının kısa aks çapı 10 mm' den daha küçüktü.

Mezenterik pannikülitin ayırıcı tanısında, karsinoid tümör, nekrotizan pankreatit, lipom, liposarkom, myelolipom, teratom, anjiyomyolipom, apse, hematom, peritoneal karsinomatozis, sarkom, lenfoma, mezenterik ödem, 
tüberküloz, desmoid tümör, Whipple hastalığı, yabanc1 cisme bağlı kronik inflamasyon gibi hastalıklar yer almaktadır (12, 17,18). Kesin tanis1 histopatolojik olarak konmaktadir. Makroskopik olarak mezenter difüz, nodüler veya multinodüler olarak büyümüş izlenir ve malign bir tümörü veya lenfomayı taklit edebilir (6).

Hastalığın spesifik bir tedavisi yoktur. Cerrahi tedavi önerilmemektedir. Hastalık takip edildiğinde kısmi veya tam düzelme gösterebileceği gibi,

\section{KAYNAKLAR}

1. Rees JR, Burgess P. Benign mesenteric lipodystrophy presenting as low abdominal pain: a case report. J Med Case Reports 2010;4:119.

2. Jura V: Mesenterite retrattile-caso clinico: risultati sperimentali, rilievi patogenetici, considerazoni cliniche. Policlinico 1927;34:535-556.

3. Amor F, Farsad M, Polato R, et al. Mesenteric panniculitis presenting with acute non-occlusive colonic ischemia. Int Arch Med 2011;4:22.

4. Gu GL, Wang SL, Wei XM, et al. Sclerosing mesenteritis as a rare cause of abdominal pain and intraabdominal mass: a case report and review of the literature. Cases J 2008;1:242.

5. Canyigit M, Koksal A, Akgoz A, et al. Multidetector-row computed tomography findings of sclerosing mesenteritis with associated diseases and its prevalence. Jpn J Radiol 2011;29:495-502.

6. Nicholson JA, Smith D, Diab M, et al. Mesenteric panniculitis in Merseyside: a case series and a review of the literature. Ann R Coll Surg Engl 2010;92:31-34. ilerleyici veya ilerleyici olmayan seyirde gösterebilir. Genelde kendini sınırlayan klinik seyir gösterir ve kendiliğinden geriler $(5,17)$. Medikal tedavide steroidler, azotioprin, siklofosfamid, tamoksifen, progesteron, kolşisin, talidomit gibi farklı ilaçlar tek başına veya birlikte kulanılmıştır. Her olgu farklı tedavi protokolüne farklı cevap vermektedir (5).

Sonuç olarak, mezenterik pannikülit mezenterik inflamasyonla karakterize kompleks bir hastalıktır. Klinik

7. Shah DM, Patel SB, Shah SR, et al. Mesenteric panniculitis: a case report and review of the literature. Indian J Radiol Imaging 2005, 15:191-192.

8. Azzam I, Croitoru S, Naschitz JE. Sclerosing mesenteritis: a diagnostic challenge. Isr Med Assoc J 2004;6:567568.

9. Daskalogiannaki M, Voloudaki A, Prassopoulos P, et al. CT evaluation of mesenteric panniculitis: prevalence and associated diseases. AJR Am J Roentgenol 2000;174:427-431.

10. Ege $G$, Akman H, Cakiroglu G. Mesenteric panniculitis associated with abdominal tuberculous lymphadenitis: a case report and review of the literature. Br J Radiol 2002 ;75:378-380.

11. van Breda Vriesman AC, Schuttevaer HM, Coerkamp EG, et al. Mesenteric panniculitis: US and CT features. Eur Radiol 2004;14:2242-2248.

12. Rosón N, Garriga V, Cuadrado M, et al. Sonographic findings of mesenteric panniculitis: correlation with CT and literature review. J Clin Ultrasound 2006;34:169-176. görünümü nonspesifik ve çok değișken olabilmektedir. Nedeni anlaşılamayan ciddi sistemik bulguları bulunan, özellikle karın semptomları olan ve akut faz reaktanlarını yüksek saptanan hastalarda ayırıc1 tanıda mutlaka akla gelmelidir. Ayrıca BT tetkikinde tanımlanan tanısal kriterler bu hastalık için spesifik olmamasına rağmen ayırıcı tanıda yardımcıdır.

13. Delgado Plasencia L, Rodríguez Ballester L, López-Tomassetti Fernández EM, et al. Mesenteric panniculitis: experience in our center. Rev Esp Enferm Dig 2007;99:291-297.

14. Issa I, Baydoun H. Mesenteric panniculitis: various presentations and treatment regimens. World J Gastroenterol 2009;15:3827-3830.

15. Horton KM, Lawler LP, Fishman EK. CT findings in sclerosing mesenteritis (panniculitis): spectrum of disease. Radiographics. 2003;23:1561-1567.

16. Sabaté JM, Torrubia S, Maideu J, et al Sclerosing mesenteritis: imaging findings in 17 patients. AJR Am J Roentgenol 1999;172:625-629.

17. Wat SY, Harish S, Winterbottom A, et al. The CT appearances of sclerosing mesenteritis and associated diseases. Clin Radiol 2006;61:652-658. 
